\title{
The Impact Evaluation of Zeolitization Parameters on the Properties of Sewage Sludge Ash
}

\author{
Jolanta Latosińska' \\ 1 Kielce University of Technology, Al. Tysiąclecia Państwa Polskiego 7, 25-341, Kielce, Poland \\ e-mail: jlatosin@tu.kielce.pl
}

\begin{abstract}
The incineration of municipal sewage sludge causes the formation of ash, which needs further utilization. The literature gives only few examples of the chemical sewage sludge ash conversion with the hydrothermal method. The effect of conversion depends on the properties of the raw material and the process parameters. According to the domestic and foreign test results of the conversion of fly ash from coal, the fusion method is more effective. The aim of the paper was to evaluate the impact of chemical sewage sludge ash conversion with the fusion method on the chosen properties of the obtained material. The applied conversion parameters were the ratio of sewage sludge ash: $\mathrm{NaOH}$, the concentration of $\mathrm{NaOH}$, the activation time and temperature as well as the crystallization temperature and time. In some of the samples, the introduction of the fusion caused the formation of the following, e.g. (hydroxy)sodalite, zeolite $\mathrm{X}$ and zeolite $\mathrm{Y}$, zeolite $\mathrm{P}$, (hydroxy)cancrinite. The temperature of the thermal treatment of sludge, the ratio of ash: $\mathrm{NaOH}$ and the crystallization time were the parameters having a statistically significant impact on the effect of zeolitization and the properties of the obtained material, but the changes of their values had little effect on the tested features of the modified ash. On the basis of the leaching of $\mathrm{Cd}, \mathrm{Cr}$ and $\mathrm{Ni}$ from the samples after the conversion it was proven that a higher temperature of the thermal treatment of sewage sludge was favourable for the formation of permanent structures.
\end{abstract}

Keywords: sewage sludge ash, synthetic zeolites, heavy metal, CEC

\section{INTRODUCTION}

In Poland there has been an increase in the contribution of thermal methods in the processing of municipal sewage sludge [General Statistic Office, 2019]. Such a trend is favoured by the limitation of the environmental usage of sludge, excessive concentrations of heavy metals in sewage sludge and the ban on landfilling of municipal sewage sludge without suitable treatment [Regulation of the Ministry of Economy, 2015]. Seven out of eleven Polish installations perform the incineration in fluidized-bed furnaces [National Waste Management Plan 2022, 2016]. The ash formed as a result of sewage sludge incineration, in comparison to the energy wastes from coal, is characterized by the composition corresponding to slag, with the simultaneously higher loss on ignition and the concentration of phosphorous [Zabielska-Adamska, 2015]. Some of the methods of ash utilization obtained from the incineration of municipal sewage sludge and coal are similar, for instance utilization in road construction or in the production of building materials [Filipiak, 2011; Kappel et al., 2017; Smol et al., 2015]. The sewage sludge ash can is a source of zeolites [Zhang et al., 2018], which have been obtained from coal fly ash since the 1980 s.

Zeolites form a spatial structure of aluminosilicates, which consist of tetrahedron networks comprising $\mathrm{AlO}_{4}$ and $\mathrm{SiO}_{4}$ bound with one another with common oxygen atoms. The developed inner structure makes them very good catalysts, sorbents and ion-exchange materials. The properties of zeolites led to their wide usage in agriculture, chemical and building industries as well as the environmental engineering [Franus, 2012]. Synthetic zeolites are most often obtained as a result of the synthesis with the hydrothermal or fusion method [Deng et al., 2016; Pimraksa et al., 
2010]. According to the literature, the synthesis of zeolites was also carried out on ash from oil shales [Bao et al., 2013].

The type of the formed zeolite depends on the properties of the raw material, in particular the contribution of the glassy phase and the value of the $\mathrm{SiO}_{2} / \mathrm{Al}_{2} \mathrm{O}_{3}$ ratio. The synthesis of zeolites is a complex process consisting in the sequence of reactions: dissolution of aluminium and silica from ash, formation of aluminosilicate gel on the undissolved particles of ash, crystallisation of zeolites and their growth. The course of the individual synthesis stages depends on such parameters as the pressure, the temperature and time of the reaction, the alkalinity of the solution and the type of the alkali. The use of different parameters of the conversion process of ash into zeolites, even within the range of one method of synthesis, prevents obtaining different crystalline forms of zeolites from the same raw material [Fan et al., 2008; Latosińska 2010; Zhang et al. 2018].

The aim of the paper was to evaluate the impact pertaining to the chemical conversion of sewage sludge ash with the fusion method on the chosen properties of the obtained material. The applied conversion parameters were the ratio of sewage sludge ash: $\mathrm{NaOH}$, the concentration of $\mathrm{NaOH}$, the activation time and temperature as well as the crystallization temperature and time.

\section{MATERIALS AND METHODS}

The ash was obtained under laboratory conditions as a result of the thermal treatment of sewage sludge in the following temperatures $600^{\circ} \mathrm{C}$ (P-600), $790^{\circ} \mathrm{C}(\mathrm{P}-790)$ and $980^{\circ} \mathrm{C}(\mathrm{P}-980)$. The sewage sludge was obtained from a mechanical-biological wastewater treatment plant in Sitkówka-Nowiny.

The analysis of the oxide composition of sewage sludge ash was performed with the X-ray fluorescence spectroscopy (XRF) method. The contribution of the amorphous substance in sewage sludge ash was measured with the internal standard method, and the phase quantitative X-ray analysis was performed with the Rietveld method using the Topas v 4.2 programme on the basis of the published crystalline structures.

The characteristics of sewage sludge ash are presented in Tables 1 and 2. The sewage sludge ash was characterized by the $\mathrm{SiO}_{2} / \mathrm{Al}_{2} \mathrm{O}_{3}$ ratio of 3.9 (P-600), 3.8 (P-790) and 3.7 (P-980). The
Table 1. Oxide composition of sewage sludge ash, $\%$ mas.

\begin{tabular}{|l|l|l|l|}
\hline $\begin{array}{l}\text { Oxide } \\
\text { composition }\end{array}$ & $\mathrm{P}-600$ & $\mathrm{P}-790$ & $\mathrm{P}-980$ \\
\hline $\mathrm{SiO}_{2}$ & $20.8 \pm 0.5$ & $25.5 \pm 0.5$ & $26.1 \pm 0.5$ \\
\hline $\mathrm{Al}_{2} \mathrm{O}_{3}$ & $5.28 \pm 0.13$ & $6.68 \pm 0.13$ & $6.98 \pm 0.13$ \\
\hline $\mathrm{P}_{2} \mathrm{O}_{6}$ & $19.4 \pm 0.5$ & $24.2 \pm 0.5$ & $25.3 \pm 0.5$ \\
\hline $\mathrm{Fe}_{2} \mathrm{O}_{3}$ & $9.45 \pm 0.3$ & $11.8 \pm 0.3$ & $12.4 \pm 0.3$ \\
\hline $\mathrm{TiO}_{2}$ & $0.725 \pm 0.025$ & $0.942 \pm 0.025$ & $0.975 \pm 0.025$ \\
\hline $\mathrm{CaO}$ & $14.3 \pm 0.4$ & $17.9 \pm 0.4$ & $18.5 \pm 0.4$ \\
\hline $\mathrm{MgO}$ & $3.72 \pm 0.09$ & $4.29 \pm 0.09$ & $4.56 \pm 0.09$ \\
\hline $\mathrm{K}_{2} \mathrm{O}$ & $1.51 \pm 0.04$ & $1.89 \pm 0.04$ & $1.98 \pm 0.04$ \\
\hline $\mathrm{SO}_{3}$ & $1.45 \pm 0.04$ & $2.14 \pm 0.06$ & $0.573 \pm 0.017$ \\
\hline $\mathrm{Na}{ }_{2} \mathrm{O}$ & $0.407 \pm 0.023$ & $0.575 \pm 0.023$ & $0.602 \pm 0.023$ \\
\hline $\mathrm{ZnO}$ & $0.355 \pm 0.009$ & $0.439 \pm 0.009$ & $0.345 \pm 0.009$ \\
\hline $\mathrm{Mn}_{2} \mathrm{O}_{3}$ & $0.104 \pm 0.005$ & $0.104 \pm 0.005$ & $0.109 \pm 0.005$ \\
\hline $\mathrm{SrO}$ & $0.046 \pm 0.002$ & $0.055 \pm 0.002$ & $0.059 \pm 0.002$ \\
\hline $\mathrm{BaO}$ & $0.091 \pm 0.006$ & $0.111+0.006$ & $0.118 \pm 0.006$ \\
\hline $\mathrm{CuO}$ & $0.048 \pm 0.003$ & $0.065 \pm 0.003$ & $0.071 \pm 0.003$ \\
\hline
\end{tabular}

sludge ash samples had different amounts of the amorphous substance, and the greatest contribution apart from the amorphous substance was for quartz (Table 2).

The solution of $3 \mathrm{M}$ concentration $\mathrm{NaOH}$ was used for the chemical sewage sludge ash conversion. The changeable parameters of the chemical conversion process were the ratio of sewage sludge ash mass to the sodium hydroxide mass, the temperature of crystallisation and the time of crystallisation (Table 3). The applied methodology of the chemical conversion was presented in Figure 1.

The analysis of the phase composition of the samples after the conversion process was performed with the X-ray diffraction method (XRD). The cation-exchange capacity (CEC) was determined on the basis of the methodology presented in [Kirov et al., 1997] with the use of $1 \mathrm{M}$ ammonium acetate. The concentration of ammonium ions in the solution was measured with the ion chromatography. The CEC of the sludge ash samples before the conversion process of conversion had the values of $49.668 \mathrm{mval} / 100 \mathrm{~g}$ (P-600), $21.914 \mathrm{mval} / 100 \mathrm{~g}$ (P-790) and below detection for P-980 respectively.

The leaching of cadmium, chrome and nickel from ash before and after the process of conversion was marked with the EP procedure [EPA Regulations on Land Disposal Restrictions, 1991]. 
Table 2. Phase quantitative analysis of sewage sludge ash and the contribution of the amorphous substance, $\%$ mas

\begin{tabular}{|l|c|c|c|}
\hline Phase & P-600 & P-790 & P-980 \\
\hline Amorphous substance & $76.71 \pm 0.62$ & $27.4 \pm 1.2$ & $13.61 \pm 0.92$ \\
\hline Quartz, $\mathrm{SiO}_{2}$ & $9.12 \pm 0.13$ & $15.27 \pm 0.21$ & $15.44 \pm 0.17$ \\
\hline Muscovite, $\mathrm{KAl}_{2}\left(\mathrm{Si}_{3} \mathrm{Al}\right) \mathrm{O}_{10}(\mathrm{OH}, \mathrm{F})_{2}$ & $4.42 \pm 0.46$ & $5.91 \pm 0.58$ & nd. \\
\hline Calcite, $\mathrm{CaCO}_{3}$ & $4.06 \pm 0.1$ & $1.36 \pm 0.13$ & nd. \\
\hline Dolomite, $\mathrm{CaMg}\left(\mathrm{CO}_{3}\right)_{2}$ & $3.28 \pm 0.11$ & nd. & nd. \\
\hline Potassium feldspar, $\mathrm{AlSi}_{3} \mathrm{O}_{8}$ & $1.72 \pm 0.29$ & $3.25 \pm 0.37$ & $4.96 \pm 0.34$ \\
\hline Rutile, $\mathrm{TiO}_{2}$ & $0.217 \pm 0.053$ & nd. & nd. \\
\hline Plagioclase, $(\mathrm{Ca}, \mathrm{Na})(\mathrm{Si}, \mathrm{Al})_{4} \mathrm{O}_{8}$ & $0.472 \pm 0.092$ & nd. & nd. \\
\hline Whitlockite, $\mathrm{Ca}_{9}(\mathrm{Ma}, \mathrm{Fe})\left(\mathrm{PO}_{4}\right)_{6}\left(\mathrm{PO} \mathrm{O}_{3} \mathrm{OH}\right)$ & nd. & $28.36 \pm 0.50$ & $34.19 \pm 0.34$ \\
\hline Stanfieldite, $\mathrm{Ca}_{4}\left(\mathrm{Mg}, \mathrm{Fe}{ }^{++} \mathrm{Mn}_{5} \mathrm{PO}_{4}\right)_{6}$ & nd. & $13.09 \pm 0.44$ & $13.05 \pm 0.32$ \\
\hline Hematite, $\mathrm{Fe}_{2} \mathrm{O}_{3}$ & nd. & nd. & $10.76 \pm 0.13$ \\
\hline Tridymite, $\mathrm{SiO}_{2}$ & nd. & $2.88 \pm 0.26$ & $7.99 \pm 0.33$ \\
\hline Maghemite, $\mathrm{Fe}_{2} \mathrm{O}_{3}$ & nd. & $1.07 \pm 0.11$ & $\mathrm{nd}$. \\
\hline Anhidrite, $\mathrm{CaSO}_{4}$ & nd. & $1.39 \pm 0.13$ & nd. \\
\hline
\end{tabular}

nd. - not detected.

Table 3. The parameters of the chemical conversion of sewage sludge ash

\begin{tabular}{|c|c|c|c|c|c|c|}
\hline \multicolumn{3}{|c|}{ Samples } & \multirow{2}{*}{$\begin{array}{c}\text { Ratio } \\
\text { ash: } \mathrm{NaOH}\end{array}$} & \multirow{2}{*}{$\begin{array}{c}\text { Activation } \\
\text { temperature, }{ }^{\circ} \mathrm{C}\end{array}$} & \multirow{2}{*}{$\begin{array}{l}\text { Crystallisation } \\
\text { temperature, }{ }^{\circ} \mathrm{C}\end{array}$} & \multirow{2}{*}{$\begin{array}{c}\text { Crystallisation time, } \\
\text { hours }\end{array}$} \\
\hline P-600 & P-790 & P-980 & & & & \\
\hline S1 & S17 & S33 & 1.0:1.4 & 60 & 60 & 6 \\
\hline S2 & S18 & S34 & $1.0: 1.4$ & 60 & 90 & 6 \\
\hline S3 & S19 & S35 & $1.0: 1.4$ & 90 & 60 & 6 \\
\hline S4 & $\mathrm{S} 20$ & S36 & 1.0:1.4 & 90 & 90 & 6 \\
\hline S5 & S21 & S37 & $1.0: 1.8$ & 60 & 60 & 6 \\
\hline S6 & S22 & S38 & $1.0: 1.8$ & 60 & 90 & 6 \\
\hline S7 & $\mathrm{S} 23$ & S39 & $1.0: 1.8$ & 90 & 60 & 6 \\
\hline S8 & S24 & S40 & $1.0: 1.8$ & 90 & 90 & 6 \\
\hline S9 & S25 & S41 & $1.0: 1.4$ & 60 & 60 & 72 \\
\hline S10 & S26 & S42 & $1.0: 1.4$ & 60 & 90 & 72 \\
\hline S11 & S27 & S43 & $1.0: 1.4$ & 90 & 60 & 72 \\
\hline S12 & S28 & S44 & $1.0: 1.4$ & 90 & 90 & 72 \\
\hline $\mathrm{S} 13$ & S29 & S45 & $1.0: 1.8$ & 60 & 60 & 72 \\
\hline S14 & $\mathrm{S} 30$ & S46 & $1.0: 1.8$ & 60 & 90 & 72 \\
\hline S15 & S31 & S47 & 1.0:1.8 & 90 & 60 & 72 \\
\hline S16 & S32 & S48 & $1.0: 1.8$ & 90 & 90 & 72 \\
\hline
\end{tabular}

The data submitted to the analysis came from the research conducted on the basis of 32 experiments from the $2^{5}$ experiment plan.

The test results pertaining to the properties of samples obtained as a result of the zeolitization constituted a set of nonparametric and parametric features. The first group consisted of the phase composition of samples, the second of the cationexchange capacity and the leaching of cadmium, chrome and nickel. In order to conduct the statistical analysis, the phase composition of samples was transcoded into a binary system. Every phase element was attributed weights from the range between 0 and 1 . Assuming that the zeolitic structures were the desirable phases, they were attributed higher weights. The values of weights for the structures not belonging to zeolites were not differentiated because they were considered parallel undesirable. The sum of arithmetical products of weights of the phase composition of samples was described as the effect of zeolitization. Due to the use of a two-level plan, three pairs of temperature levels of the thermal treatment were applied: $600^{\circ} \mathrm{C}$ and $790^{\circ} \mathrm{C}, 790^{\circ} \mathrm{C}$ and $980^{\circ} \mathrm{C}, 600^{\circ} \mathrm{C}$ and $980^{\circ} \mathrm{C}$.

The coefficients of the regression function were determined with the least squares method, while the selection of elements constituting the 


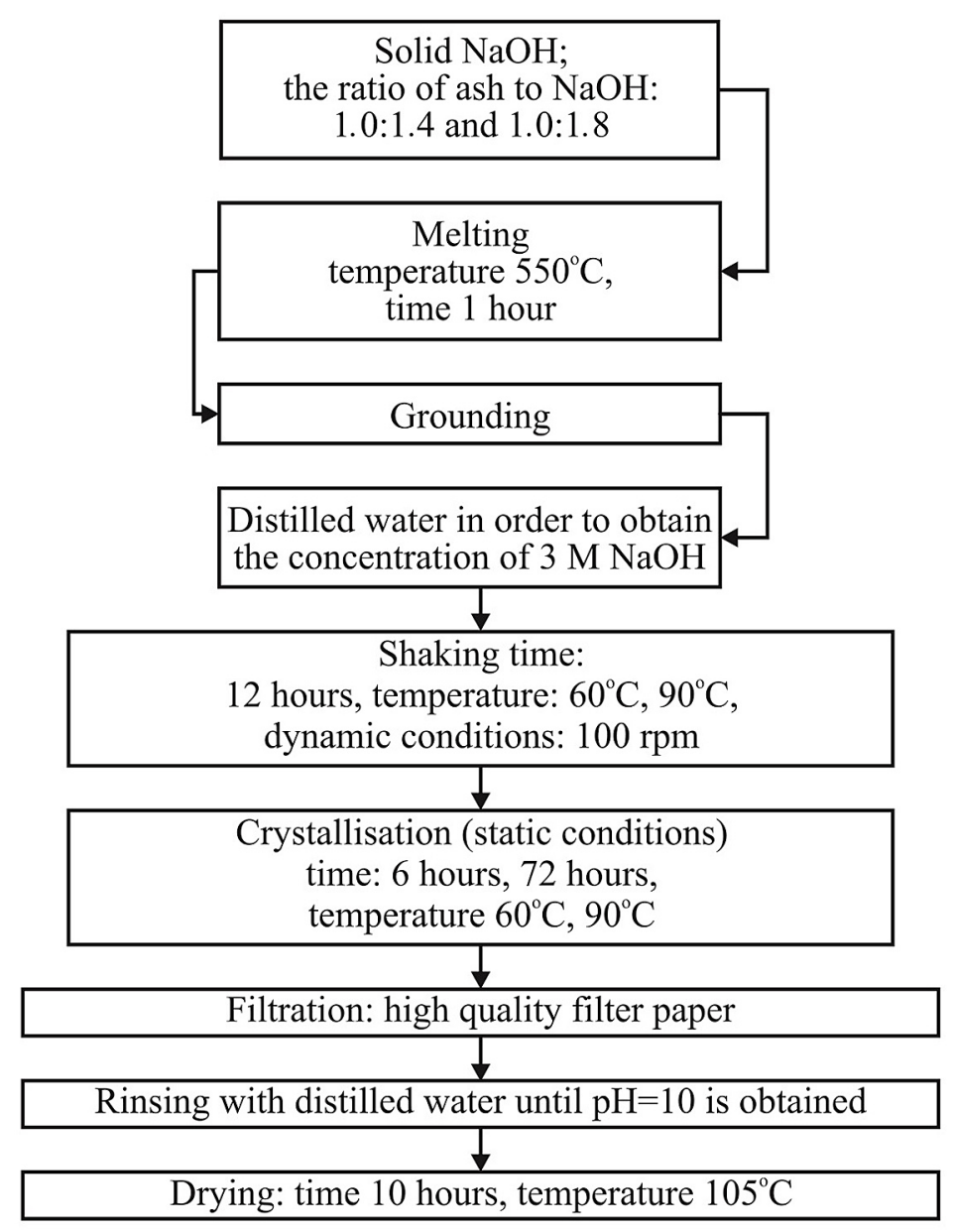

Figure 1. The procedure of chemical conversion of sewage sludge ash.

final form of the model was conducted with the step selection method. The significance of the coefficients of the regression function in the estimated regression function was verified with the F test. The elimination of the statistically insignificant elements of the regression function was performed with the assumption of the limit value for the level of significance at $p=0.1$. The statistical calculations were carried out in the SAS 9.3 software.

The corrected coefficient of determination $\breve{\mathrm{R}}^{2}$ including the correction, resulting from the different number of elements in the model, was introduced in order to evaluate the compliance of the estimated regression model with the experimental data. The corrected coefficient of determination $\check{\mathrm{R}}^{2}$ applies the values from the range between $0-1$. One can speak of the adjustment of the model to the data:

- weak, when $0.0<\check{\mathrm{R}}^{2} \leq 0.3$

- satisfactory, when $0.3<\check{\mathrm{R}}^{2} \leq 0.6$

- good, when $0.6<\breve{\mathrm{R}}^{2} \leq 0.8$

- very good, when $0.8<\check{\mathrm{R}}^{2} \leq 1.0$.

\section{RESULTS AND DISCUSSION}

The crystalline phases of samples after the chemical conversion were presented in tables 4-6. The application of the fusion method of the P-600 ash in the option with the 6-hour crystallisation time, the ratio of sewage sludge ash:NaOH-1:1.4 and for all the applied temperatures of activation and crystallisation did not cause the crystallisation of the zeolitic structures (S1-S4). The change in the ratio of sewage sludge ash: $\mathrm{NaOH}$ from 1:1.4 to $1: 1.8$ resulted in the formation of (hydroxy)sodalite in two samples (S7, S8). The remaining parameters of the process of the synthesis of samples S7 and S8 differed only in the value of the crystallisation time.

The prolongation of the crystallisation time up to 72 hours for the samples with the ratio of sewage sludge ash:NaOH-1:1.4 resulted in the crystallisation of only one zeolitic structure zeolite P (S10, S12), which was accompanied by apatite, magnetite and quartz. The synthesis parameters of these samples differed only in the 
Table 4. Crystalline phases obtained as a result of the zeolitization of the P-600 sewage sludge ash.

\begin{tabular}{|c|c|c|c|c|c|c|c|}
\hline $\begin{array}{c}\text { Sample } \\
\text { number }\end{array}$ & Apatite & $\begin{array}{c}\text { Hydroxy) sodalite/ } \\
\text { Sodalite }\end{array}$ & Zeolite Y & Zeolite X & Zeolite P & Magnetite & Quartz \\
\hline S1 & + & - & - & - & - & + & + \\
\hline S2 & + & - & - & - & - & + & + \\
\hline S3 & + & - & - & - & - & + & + \\
\hline S4 & + & - & - & - & - & + & + \\
\hline S5 & + & - & - & - & - & + & + \\
\hline S6 & + & - & + & - & - & - & + \\
\hline S7 & + & + & - & - & - & + & + \\
\hline S8 & + & + & - & - & - & + & + \\
\hline S9 & + & - & - & - & - & + & + \\
\hline S10 & + & - & - & - & + & + & + \\
\hline S11 & + & - & - & - & - & + & + \\
\hline S12 & + & - & - & - & + & + & + \\
\hline S13 & + & - & - & + & - & + & + \\
\hline S14 & + & + & - & + & - & + & - \\
\hline S15 & + & - & - & - & + & + & + \\
\hline S16 & + & + & - & - & - & + & + \\
\hline
\end{tabular}

Table 5. Crystalline phases obtained as a result of the zeolitization of the P-790 sewage sludge ash

\begin{tabular}{|c|c|c|c|c|c|}
\hline Sample number & Apatite & (Hydroxy) sodalite/Sodalite & Zeolite X & Magnetite & Quartz \\
\hline S17 & + & + & - & - & - \\
\hline S18 & + & + & - & - & - \\
\hline S19 & + & + & - & - & + \\
\hline S20 & + & + & - & - & + \\
\hline S21 & + & + & - & - & - \\
\hline S22 & + & + & - & - & - \\
\hline S23 & + & + & - & - & - \\
\hline S24 & + & - & + & - & - \\
\hline S25 & + & + & - & - & + \\
\hline S26 & + & + & - & - & + \\
\hline S27 & + & + & + & - & + \\
\hline S28 & + & + & - & - & - \\
\hline S29 & + & + & - & - & + \\
\hline S30 & + & + & - & + & - \\
\hline S31 & + & + & + & - & - \\
\hline S32 & + & + & - & - & \\
\hline
\end{tabular}

value of the activation temperature. The crystallisation temperature $60^{\circ} \mathrm{C}$ did not cause the crystallisation of zeolitic structures (S9, S11). The samples of (hydroxy)sodalite (S14, S16), zeolite $\mathrm{X}(\mathrm{S} 13, \mathrm{~S} 14)$ and zeolite $\mathrm{P}(\mathrm{S} 15)$ had the ratio of ash: $\mathrm{NaOH}$ amounting to $1: 1.8$.

The chemical conversion caused the synthesis of zeolitic phases in all samples of P-790 sewage sludge ash. Hydroxysodalite was found in S17-S24 and S26-S32 samples, while zeolite X in the S25, S29 samples. The unreacted mineral phase from ash P-790, i.e. quartz, was also found in the product of the synthesis reaction.
The reflexes characteristic for (hydroxy)sodalite accompanied by apatite (S17-S24) and quartz (S19-S20) were found in all samples of the P-790 sewage sludge ash after the 6-hour crystallisation time, regardless of the values of the remaining process parameters. The prolongation of the crystallisation time up to 72 hours translated into the identification of zeolite $X$ in the samples of the lowest values of the activation temperature and the crystallisation temperature, in the sample with the ratio of sewage sludge ash: $\mathrm{NaOH}-1: 1.4$ (S25) and in the sample with the ratio of sewage sludge ash: $\mathrm{NaOH}-1: 1.8(\mathrm{~S} 32)$. 
The chemical conversion of the P-980 sewage sludge ash caused that (hydroxy)sodalite and apatite were found in the S33-S48 samples, and hydroxycancrinite in the S39 sample (tab.6). The prolongation of the crystallisation time up to 72 hours caused that zeolite $\mathrm{X}$ was found in samples S41 and S45. The stage of activation and crystallisation for both samples was realized at $60^{\circ} \mathrm{C}$. The parameters of the process of the synthesis S41 and S45 differed only in the ratio of sewage sludge ash: $\mathrm{NaOH}$ (tab.3).

The results proved the fact that the change of process conditions does not always cause the increase of the efficiency of the formation of a particular zeolite. The synthesis of other structures often begins under particular conditions. According to [Fan et al., 2008], zeolite X together with the change of zeolitization conditions, i.e. the change in the ratio of sewage sludge ash: $\mathrm{NaOH}$, can pass into the form of (hydroxy)sodalite. Smaller number of crystalline phases in the P-980 sewage sludge ash in comparison to the P-600 and P-790 sewage sludge ash translated into their smaller number in the samples after the conversion.

The chemical conversion caused the increase in the cation-exchange capacity of samples. The values were in the range from $109.195 \mathrm{mval} / 100 \mathrm{~g}$ (S48) to $268.282 \mathrm{mval} / 100 \mathrm{~g}$ (S12, Table 7).

The comparison of the cation-exchange capacity of the P-600 sewage sludge ash and samples after the process of conversion demonstrates that S1-S16 samples were characterized by higher values of this parameter. Similarly, the comparison of the cation-exchange capacity of the P-790 and P-980 sewage sludge ashes with the S17-S32 and S33-S48 samples, respectively, proves the increase of the value of the cation-exchange capacity as a result of the zeolitization with the fusion method (Table 7). The change of the ratio of sewage sludge ash:NaOH from 1:1.4 to $1: 1.8$ caused that the increase of the contribution of the sodium hydroxide was accompanied by the decrease of the cation-exchange capacity, regardless of the temperature of the thermal treatment of sewage sludge (Table 7).

The highest value of the cation-exchange capacity was found for the S12 sample. The S12 sample with the ratio of sewage sludge ash:NaOH-1:1.4 was formed as a result of the activation of the $\mathrm{P}-600$ ash in $90^{\circ} \mathrm{C}$ and crystallisation in $90^{\circ} \mathrm{C}$. The comparison of the cationexchange capacities of the samples after the conversion of the P-600 ash with the analogical samples after the zeolitization of the P-790 and P-980 ash samples also proved that the conversion of the P-600 ash caused the highest increase of the cation-exchange capacity (Table 7).

The lack of cadmium was discovered in some of the eluates of the S1-S48 samples. In other cases, the concentration of cadmium was from $0.0051 \mathrm{mg} / \mathrm{dm}^{3}$ (S16) to $1.5212 \mathrm{mg} / \mathrm{dm}^{3}$ (S10); thus, cadmium exceeded the admissible value of $0.005 \mathrm{mg} / \mathrm{dm}^{3}$ determined by the regulation [Regulation of the Ministry of Health, 2017].

Nickel was not found in eluates of some of the S1-S48 samples. In the remaining eluates, the concentration of nickel was from $0.008 \mathrm{mg} / \mathrm{dm}^{3}$ (S27) to $1.4741 \mathrm{mg} / \mathrm{dm}^{3}$ (S39). The prolongation

Table 6. Crystalline phases obtained as a result of the zeolitization of the P-980 sewage sludge ash

\begin{tabular}{|c|c|c|c|c|}
\hline Sample number & Apatite & (Hydroxy) sodalite/Sodalite & Zeolite X & Hydroxycancrinite \\
\hline S33 & + & - & - & - \\
\hline S34 & + & + & - & - \\
\hline S35 & + & + & - & - \\
\hline S36 & + & + & - & - \\
\hline S37 & + & + & - & - \\
\hline S38 & + & + & - & - \\
\hline S39 & + & + & - & + \\
\hline S40 & + & + & - & - \\
\hline S41 & + & + & + & - \\
\hline S42 & + & + & - & - \\
\hline S43 & + & + & - & - \\
\hline S44 & + & + & - & - \\
\hline S45 & + & + & + & - \\
\hline S46 & + & + & - & - \\
\hline S47 & + & + & - & - \\
\hline S48 & + & + & - & - \\
\hline
\end{tabular}


Table 7. Cation-exchange capacity and the leaching of cadmium, chrome and nickel from sewage sludge ash after the conversion, $\mathrm{mg} / \mathrm{dm}^{3}$

\begin{tabular}{|c|c|c|c|c|}
\hline $\begin{array}{l}\text { Sample } \\
\text { number }\end{array}$ & CEC & Cadmium & Chrome & Nickel \\
\hline $\mathrm{S} 1$ & 201.144 & $0.1838 \pm 0.0123$ & $0.0054 \pm 0.0039$ & $1.0494 \pm 0.1435$ \\
\hline $\mathrm{S} 2$ & 207.780 & $0.1823 \pm 0.0173$ & $0.0081 \pm 0.0014$ & $0.8509 \pm 0.0834$ \\
\hline S3 & 211.356 & $0.1829 \pm 0.0018$ & $0.0076 \pm 0.0039$ & $1.566 \pm 0.1206$ \\
\hline S4 & 205.834 & $0.1995 \pm 0.0107$ & $0.0281 \pm 0.0078$ & $0.8693 \pm 0.1285$ \\
\hline S5 & 176.067 & nd. \pm 0.0126 & $0.0277 \pm 0.0082$ & $2.2114 \pm 0.0453$ \\
\hline S6 & 195.315 & $0.211 \pm 0.0298$ & $0.0194 \pm 0.0086$ & nd. \pm 0.0152 \\
\hline S7 & 179.637 & $0.2688 \pm 0.0326$ & $0.0322 \pm 0.0070$ & $0.3656 \pm 0.0156$ \\
\hline S8 & 171.215 & $0.3507 \pm 0.0436$ & $0.0193 \pm 0.0087$ & $1.2098 \pm 0.1101$ \\
\hline s9 & 189.562 & nd. \pm 0.0033 & nd. \pm 0.0057 & nd. \pm 0.0182 \\
\hline S10 & 264.884 & $1.5212 \pm 0.4409$ & $0.6375 \pm 0.1387$ & $0.2376 \pm 0.0028$ \\
\hline $\mathrm{S} 11$ & 209.720 & $0.4156 \pm 0.0605$ & $0.094 \pm 0.0248$ & $0.0533 \pm 0.012$ \\
\hline $\mathrm{S} 12$ & 268.282 & $0.3387 \pm 0.0255$ & $0.0532 \pm 0.0028$ & nd. \pm 0.0281 \\
\hline $\mathrm{S} 13$ & 193.094 & $0.4242 \pm 0.0289$ & $0.0311 \pm 0.0047$ & $0.207 \pm 0.0571$ \\
\hline S14 & 182.522 & $0.0571 \pm 0.0046$ & $0.0632 \pm 0.0054$ & $0.5439 \pm 0.0446$ \\
\hline S15 & 228.505 & $0.0153 \pm 0.0119$ & $0.0357 \pm 0.0023$ & $0.4972 \pm 0.0487$ \\
\hline S16 & 194.116 & $0.0051 \pm 0.00137$ & $0.0020 \pm 0.0009$ & $0.0375 \pm 0.01619$ \\
\hline S17 & 170.796 & $0.2275 \pm 0.0270$ & $0.2865 \pm 0.0069$ & $0.1362 \pm 0.0518$ \\
\hline S18 & 167.268 & $0.3686 \pm 0.0351$ & $0.2682 \pm 0.0063$ & $0.1238 \pm 0.0461$ \\
\hline S19 & 158.998 & $0.1922 \pm 0.0221$ & $0.3423 \pm 0.0061$ & $1.2823 \pm 0.0018$ \\
\hline S20 & 187.426 & $0.4896 \pm 0.0279$ & $0.3036 \pm 0.00561$ & $0.3569 \pm 0.0773$ \\
\hline S21 & 131.931 & $0.0168 \pm 0.0287$ & $0.2967 \pm 0.0083$ & $0.6507 \pm 0.0589$ \\
\hline $\mathrm{S} 22$ & 145.777 & $0.2253 \pm 0.0225$ & $0.187 \pm 0.0083$ & $0.5558 \pm 0.0853$ \\
\hline $\mathrm{S} 23$ & 125.439 & $0.1142 \pm 0.0078$ & $0.3281 \pm 0.0040$ & $0.1082 \pm 0.0899$ \\
\hline S24 & 142.063 & $0.5021 \pm 0.0049$ & $0.2849 \pm 0.0059$ & $0.7052 \pm 0.0505$ \\
\hline $\mathrm{S} 25$ & 146.478 & nd. \pm 0.0023 & $0.7222 \pm 0.0019$ & $0.413 \pm 0.0867$ \\
\hline S26 & 206.449 & nd. \pm 0.0050 & $0.1379 \pm 0.0096$ & nd. \pm 0.0508 \\
\hline S27 & 179.748 & nd. \pm 0.0060 & $0.1643 \pm 0.0153$ & $0.008 \pm 0.0743$ \\
\hline $\mathrm{S} 28$ & 166.700 & $0.0671 \pm 0.0179$ & $0.0742 \pm 0.0072$ & nd. \pm 0.07192 \\
\hline S29 & 147.406 & nd. \pm 0.0041 & $0.1744 \pm 0.0066$ & nd. \pm 0.0192 \\
\hline S30 & 142.948 & nd. \pm 0.0065 & $0.0406 \pm 0.0039$ & nd. \pm 0.0756 \\
\hline S31 & 151.234 & nd. \pm 0.0112 & $0.1024 \pm 0.0082$ & nd. \pm 0.0465 \\
\hline S32 & 136.875 & nd. \pm 0.0153 & $0.1893 \pm 0.0174$ & nd. \pm 0.0129 \\
\hline S33 & 137.893 & $0.2809 \pm 0.0282$ & $0.1193 \pm 0.0029$ & $1.3987 \pm 0.0682$ \\
\hline S34 & 197.557 & $0.2341 \pm 0.0268$ & $0.3672 \pm 0.0070$ & $1.0627 \pm 0.0508$ \\
\hline S35 & 161.676 & $0.6397 \pm 0.0101$ & $3.8496 \pm 0.0445$ & $0.8331 \pm 0.0705$ \\
\hline S36 & 161.556 & $0.5916 \pm 0.0053$ & $0.1973 \pm 0.0061$ & $1.2554 \pm 0.0453$ \\
\hline S37 & 111.557 & $0.52 \pm 0.0004$ & $0.1692 \pm 0.0022$ & $1.1361 \pm 0.0377$ \\
\hline S38 & 145.289 & $0.3333 \pm 0.0310$ & $0.2052 \pm 0.0008$ & $0.7071 \pm 0.0383$ \\
\hline S39 & 109.278 & $0.3811 \pm 0.0427$ & $5.6743 \pm 0.0946$ & $1.4741 \pm 0.0807$ \\
\hline $\mathrm{S} 40$ & 131.085 & $0.4241 \pm 0.0336$ & $0.1542 \pm 0.0021$ & $1.0804 \pm 0.0868$ \\
\hline S41 & 134.695 & nd. \pm 0.0244 & $0.2872 \pm 0.0051$ & $0.1496 \pm 0.0225$ \\
\hline S42 & 154.935 & $0.2172 \pm 0.0189$ & $0.274 \pm 0.0042$ & $0.0854 \pm 0.0473$ \\
\hline$S 43$ & 161.322 & $0.2595 \pm 0.0434$ & $0.165 \pm 0.0059$ & $0.043 \pm 0.0170$ \\
\hline S44 & 157.451 & $0.1897 \pm 0.0176$ & $0.2492 \pm 0.0065$ & nd. \pm 0.0288 \\
\hline$S 45$ & 123.691 & $0.1761 \pm 0.0137$ & $0.0758 \pm 0.0057$ & $0.0315 \pm 0.0423$ \\
\hline S46 & 130.452 & $0.1644 \pm 0.010$ & $0.1913 \pm 0.0010$ & $0.164 \pm 0.0058$ \\
\hline S47 & 114.992 & $0.2296 \pm 0.0394$ & $0.0952 \pm 0.0016$ & $0.8314 \pm 0.0828$ \\
\hline S48 & 109.195 & $0.1852 \pm 0.0205$ & $0.2397 \pm 0.0081$ & $0.8803 \pm 0.0745$ \\
\hline
\end{tabular}

nd. - not detected 
of the crystallisation time of the P-600 ash caused a decrease in the concentration of nickel (S1-S16). In the eluates after the conversion of the P-790 ash samples with the 6-hour crystallisation time, the concentration of nickel was from $0.1082 \mathrm{mg} / \mathrm{dm}^{3}$ (P75) to $1.2823 \mathrm{mg} / \mathrm{dm}^{3}$ (P71). Exclusively one sample of the 72-hour crystallisation time of the P-790 ash had the value over $0.4 \mathrm{mg} / \mathrm{dm}^{3}$ (S25). Thus, the prolongation of the crystallisation time of the samples from the P-980 ash was accompanied by the decrease of the nickel concentration in eluates (tab. 7). In the majority of the eluates of the S1-S48 samples, the concentration of nickel exceeded $0.02 \mathrm{mg} / \mathrm{dm}^{3}$, i.e. the concentration breakpoint for drinking water [Regulation of the Ministry of Health, 2017].

Chromium was the heavy metal with relatively small values in the eluates of the S1-S48 samples. The lowest concentration of chromium was found in the eluate of the S16 sample$0.002 \mathrm{mg} / \mathrm{dm}^{3}$, and the highest in S39- 5.6743 $\mathrm{mg} / \mathrm{dm}^{3}$. Only in the eluate of the S9 sample, chromium was not detected. The limited value of chromium $-0.05 \mathrm{mg} / \mathrm{dm}^{3}$ according to [Regulation of the Ministry of Health, 2017] - was exceeded in the eluates of the following samples: S10-S12, S12, S17-S29, S31-S48.

Linear models for zeolitization with the fusion method with $\mathrm{NaOH}$ were presented in tables $8-12$. The statistical analysis proved that the formation of zeolitic structures statistically significantly depends on the temperature of the thermal treatment of sludge and the ratio of sewage sludge ash: $\mathrm{NaOH}$. The increase in the values of both independent variables has a favourable influence on the effect of zeolitization. For the P-600 and P-980 samples, the time of crystallisation is also statistically significant (tab.8). The values of the corrected coefficient of determination for both analysed models prove their good adjustment $\left(\breve{\mathrm{R}}^{2}=\right.$ 0.629 - temperature $600^{\circ} \mathrm{C}$ and $790^{\circ} \mathrm{C} ; \check{\mathrm{R}}^{2}=0.6971$ - temperature $600^{\circ} \mathrm{C}$ and $980^{\circ} \mathrm{C}$; tab.8).

A model was obtained for the samples from the set of P-790 and P-980 sewage sludge ashes in which the effectiveness of zeolitization depends on the ratio of sewage sludge ash: $\mathrm{NaOH}$, the temperature of the thermal treatment and the crystallisation temperature. The increase in the first of the two mentioned independent variables has a negative impact on the effect of zeolitization. However, the corrected coefficient of determination $\breve{\mathrm{R}}^{2}=0.2139$ is the evidence of the poor adjustment of the model (tab.8).

On the basis of the elimination of statistically insignificant variables, it was proven that the value of the cation-exchange capacity is influenced by the ratio of sewage sludge ash: $\mathrm{NaOH}$, the temperature of crystallisation and the temperature of the thermal treatment of sludge. According to the obtained models, the increase of the crystallisation temperature will cause the increase in the value of the cation-exchange capacity. However, the increase in the temperature of the thermal treatment of sludge will cause the decrease in the value of the cation-exchange capacity. The increase in the value of the ratio of sewage sludge

Table 8. The estimation of the parameters of models describing the effect of zeolitization.

\begin{tabular}{|c|c|c|c|c|}
\hline Independent variable & Parameter evaluation & Standard error & Statistical value $\mathrm{F}$ & Pr. $>$ F (value $p)$ \\
\hline \multicolumn{5}{|c|}{ Temperature of the thermal treatment of sludge: $600^{\circ} \mathrm{C}, 790^{\circ} \mathrm{C}$} \\
\hline Intercept & -1.24008 & 0.29936 & 17.16 & 0.0003 \\
\hline Temperature of thermal treatment & 0.00095066 & 0.00014400 & 43.58 & $<0.0001$ \\
\hline Sewage sludge ash: $\mathrm{NaOH}$ & 0.01523 & 0.00460 & 10.97 & 0.0025 \\
\hline \multicolumn{5}{|c|}{ Coefficient of determination $\mathrm{R}^{2}=0.6529$; Corrected coefficient of determination $\mathrm{R}^{2}=0.629$} \\
\hline \multicolumn{5}{|c|}{ Temperature of the thermal treatment of sludge: $790^{\circ} \mathrm{C}, 980^{\circ} \mathrm{C}$} \\
\hline Intercept & -0.07651 & 0.25844 & 0.09 & 0.7694 \\
\hline Temperature of thermal treatment & 0.00023355 & 0.00011738 & 3.96 & 0.0565 \\
\hline Sewage sludge ash: $\mathrm{NaOH}$ & 0.00725 & 0.00375 & 3.74 & 0.0633 \\
\hline Temperature of crystallisation & -0.00144 & 0.00074340 & 3.74 & 0.0633 \\
\hline \multicolumn{5}{|c|}{ Coefficient of determination $\mathrm{R}^{2}=0.2900 ;$ Corrected coefficient of determination $\mathrm{R}^{2}=0.2139$} \\
\hline \multicolumn{5}{|c|}{ Temperature of the thermal treatment of sludge: $600^{\circ} \mathrm{C}, 980^{\circ} \mathrm{C}$} \\
\hline Intercept & -1.00025 & 0.30184 & 10.98 & 0.0025 \\
\hline Temperature of thermal treatment & 0.00059211 & 0.00007539 & 61.68 & $<0.0001$ \\
\hline Sewage sludge ash: $\mathrm{NaOH}$ & 0.01428 & 0.00481 & 8.80 & 0.0061 \\
\hline Time of crystallisation & 0.00085227 & 0.00043406 & 3.86 & 0.0596 \\
\hline \multicolumn{5}{|c|}{ Coefficient of determination $\mathrm{R}^{2}=0.7264$; Corrected coefficient of determination $\mathrm{R}^{2}=0.6971$} \\
\hline
\end{tabular}


ash: $\mathrm{NaOH}$ will also translate into the decrease in the cation-exchange capacity. The time of crystallisation was the statistically significant parameter for the samples of lower range of temperatures of the thermal treatment of sludge. According to the model, the prolongation of the crystallisation time will cause the increase in the cation-exchange capacity. The values of the corrected coefficient of determination are the evidence of the good adjustment of the model (tab.9).

It was proven that the temperature of the thermal treatment of sludge and the time of crystallisation, and in the case of cadmium also the temperature of activation are the statistically significant parameters in the greatest number of models describing the leaching of the determined heavy metals. In three cases of cadmium and chrome leaching, no models were obtained because none of the parameters occurred to be statistically significant (tab.10-tab.11). It was the consequence of the fact that no tested heavy metals were detected in eluates of some of the samples. The abovementioned fact is favourable from the perspective of the use of the material. The time of crystallisation is the factor the prolongation of which causes the decrease of the value of the leaching of cadmium and nickel (tab.9.10, tab.12). The recognition of the influence of crystallisation on the leaching of heavy metals requires determining the concentrations of metals in the liquids obtained during the rinsing of sludge ash after the process of zeolitization. The increase of the temperature of the thermal treatment of sludge, as described by most of the obtained models, has a favourable influence on the decrease of the value of leaching of heavy metals (tab.10-tab.12). The statement above converges with the test results presented in [Latosińska, 2017; Latosińska, 2019, Latosińska et al. 2012]. In the mentioned papers, it was proven that the factor decreasing the leaching and the mobility of heavy metals from sewage sludge ash is a higher temperature of sludge

Table 9. The estimation of the parameters of models describing the cation-exchange capacity.

\begin{tabular}{|c|c|c|c|c|}
\hline Independent variable & Parameter evaluation & Standard error & Statistical value $\mathrm{F}$ & Pr.>F (value $p)$ \\
\hline \multicolumn{5}{|c|}{ Temperature of the thermal treatment of sludge: $600^{\circ} \mathrm{C}, 790^{\circ} \mathrm{C}$} \\
\hline Intercept & 640.66223 & 70.75668 & 81.98 & $<0.0001$ \\
\hline Temperature of thermal treatment & -0.25378 & 0.03313 & 58.66 & $<0.0001$ \\
\hline Sewage sludge ash:NaOH & -5.23195 & 1.05765 & 24.47 & $<0.0001$ \\
\hline Temperature of crystallisation & 0.38404 & 0.20985 & 3.35 & 0.0783 \\
\hline Time of crystallisation & 0.21825 & 0.09539 & 5.24 & 0.0302 \\
\hline \multicolumn{5}{|c|}{ Coefficient of determination $\mathrm{R}^{2}=0.7726$; Corrected coefficient of determination $\mathrm{R}^{2}=0.7389$} \\
\hline \multicolumn{5}{|c|}{ Temperature of the thermal treatment of sludge: $790^{\circ} \mathrm{C}, 980^{\circ} \mathrm{C}$} \\
\hline Intercept & 547.01022 & 55.71051 & 96.41 & $<0.0001$ \\
\hline Temperature of thermal treatment & -0.08714 & 0.02530 & 11.86 & 0.0018 \\
\hline Sewage sludge ash:NaOH & -5.79323 & 0.80766 & 51.45 & $<0.0001$ \\
\hline Temperature of crystallisation & 0.44978 & 0.16025 & 7.88 & 0.0090 \\
\hline \multicolumn{5}{|c|}{ Coefficient of determination $\mathrm{R}^{2}=0.7177$; Corrected coefficient of determination $\mathrm{R}^{2}=0.6875$} \\
\hline \multicolumn{5}{|c|}{ Temperature of the thermal treatment of sludge: $600^{\circ} \mathrm{C}, 980^{\circ} \mathrm{C}$} \\
\hline Intercept & 611.72077 & 74.15311 & 68.05 & $<0.0001$ \\
\hline Temperature of thermal treatment & -0.17046 & 0.01805 & 89.21 & $<0.0001$ \\
\hline Sewage sludge ash:NaOH & -5.56119 & 1.15215 & 23.30 & $<0.0001$ \\
\hline Temperature of crystallisation & 0.48600 & 0.22860 & 4.52 & 0.0425 \\
\hline \multicolumn{5}{|c|}{ Coefficient of determination $\mathrm{R}^{2}=0.8069$; Corrected coefficient of determination $\mathrm{R}^{2}=0.7863$} \\
\hline
\end{tabular}

Table 10. The estimation of the parameters of the model describing the leaching of cadmium.

\begin{tabular}{|c|c|c|c|c|}
\hline Independent variable & Parameter evaluation & Standard error & Statistical value $F$ & Pr. $>F$ (value $p$ ) \\
\hline \multicolumn{5}{|c|}{ Temperature of the thermal treatment of sludge: $790^{\circ} \mathrm{C}, 980^{\circ} \mathrm{C}$} \\
\hline Intercept & -0.6289 & 0.20724 & 9,21 & 0,0052 \\
\hline Temperature of thermal treatment & 0.00086286 & 0.00020415 & 17.86 & 0.0002 \\
\hline Temperature of activation & 0.00313 & 0.00129 & 5,85 & 0,0223 \\
\hline Time of crystallisation & -0.00384 & 0.00058771 & 42,63 & $<0,0001$ \\
\hline
\end{tabular}


Table 11. The estimation of the parameters of models describing the leaching of chrome.

\begin{tabular}{|c|c|c|c|c|}
\hline Independent variable & Parameter evaluation & Standard error & Statistical value $\mathrm{F}$ & Pr. $>F($ value $p)$ \\
\hline \multicolumn{5}{|c|}{ Temperature of the thermal treatment of sludge: $600^{\circ} \mathrm{C}, 790^{\circ} \mathrm{C}$} \\
\hline Intercept & -0.49362 & 0.20386 & 5.86 & 0.0217 \\
\hline Temperature of thermal treatment & 0.00093359 & 0.00029062 & 10.32 & 0.0031 \\
\hline \multicolumn{5}{|c|}{ Coefficient of determination $R^{2}=0.2559$; Corrected coefficient of determination $\check{R}^{2}=0.2311$} \\
\hline \multicolumn{5}{|c|}{ Temperature of the thermal treatment of sludge: $600^{\circ} \mathrm{C}, 980^{\circ} \mathrm{C}$} \\
\hline Intercept & -1.04359 & 0.85680 & 1.48 & 0.2327 \\
\hline Temperature of thermal treatment & 0.00185 & 0.00105 & 3.08 & 0.0895 \\
\hline
\end{tabular}

Table 12. The estimation of the parameters of models describing the leaching nickel.

\begin{tabular}{|c|c|c|c|c|}
\hline Independent variable & Parameter evaluation & Standard error & Statistical value F & Pr.>F (value $p)$ \\
\hline \multicolumn{5}{|c|}{ Temperature of the thermal treatment of sludge: $600^{\circ} \mathrm{C}, 790^{\circ} \mathrm{C}$} \\
\hline Intercept & 2.03478 & 0.55846 & 13.28 & 0.0010 \\
\hline Temperature of thermal treatment & -0.00176 & 0.00078613 & 5.03 & 0.0328 \\
\hline Time of crystallisation & -0.00951 & 0.00226 & 17.66 & 0.0002 \\
\hline \multicolumn{5}{|c|}{ Coefficient of determination $\mathrm{R}^{2}=0.439$; Corrected coefficient of determination $\check{\mathrm{R}}^{2}=0.4003$} \\
\hline \multicolumn{5}{|c|}{ Temperature of the thermal treatment of sludge: $790^{\circ} \mathrm{C}, 980^{\circ} \mathrm{C}$} \\
\hline Intercept & -1.11501 & 0.53840 & 4.29 & 0.0474 \\
\hline Temperature of thermal treatment & 0.00223 & 0.00060013 & 13.86 & 0.0008 \\
\hline Time of crystallisation & -0.00972 & 0.00173 & 31.63 & $<0.0001$ \\
\hline \multicolumn{5}{|c|}{ Coefficient of determination $\mathrm{R}^{2}=0.6107$; Corrected coefficient of determination $\check{\mathrm{R}}^{2}=0.5839$} \\
\hline \multicolumn{5}{|c|}{ Temperature of the thermal treatment of sludge: $600^{\circ} \mathrm{C}, 980^{\circ} \mathrm{C}$} \\
\hline Intercept & 1.14249 & 0.11266 & 102.84 & $<0.0001$ \\
\hline Time of crystallisation & -0.01260 & 0.00221 & 32.66 & $<0.0001$ \\
\hline \multicolumn{5}{|c|}{ Coefficient of determination $\mathrm{R}^{2}=0.5212$; Corrected coefficient of determination $\mathrm{R}^{2}=0.5053$} \\
\hline
\end{tabular}

incineration [Latosińska, 2017; Latosińska, 2019, Latosińska et al. 2012].

The models with good adjustment describe the variability of the leaching of cadmium. The models with the satisfactory adjustment describe the variability of the leaching of nickel. In the case of leaching of chrome, the obtained models had poor adjustment.

\section{CONCLUSIONS}

The results of the research on the impact of the chemical conversion parameters on the properties of sewage sludge ash allow drawing the following conclusions:

- the conversion with the fusion method cause the formation of the following in some of the samples: (hydroxy)sodalite, zeolite $\mathrm{X}$, zeolite $\mathrm{Y}$, zeolite $\mathrm{P}$ and (hydroxy)cancrinite,

- regardless of the process parameters and the temperature of the thermal treatment of sludge, no monomineral zeolites were obtained,
- the formation of zeolitic structures statistically significantly depends on the temperature of the thermal treatment of sludge and the ratio of sewage sludge ash: $\mathrm{NaOH}$. The time of crystallisation and the temperature of crystallisation are also statistically significant,

- the values of the cation-exchange capacity statistically significantly depend on: the ratio sewage sludge ash: $\mathrm{NaOH}$, the temperature of crystallisation, the temperature of the thermal treatment of sludge and the time of crystallisation,

- the temperature of the thermal treatment of sludge and the time of crystallisation, and in the case of cadmium also the temperature of activation are the statistically significant parameters in the greatest number of models describing the leaching of the determined heavy metals,

- the cases of the lack of statistically significant factors influencing the leaching of cadmium and chrome are the consequence of the fact 
that no tested heavy metals were detected in the eluates of some of the samples,

- higher temperature of the thermal treatment of sewage sludge is favourable for the formation of permanent structures,

- the temperature of the thermal treatment of sewage sludge, being the parameter which influences the effect of zeolitization and the properties of the obtained material, is statistically significant, but the change of its value has little impact on the tested features of the modified ash. Taking into account the possible changes of the temperature of the thermal treatment of sludge in the installation, e.g. as a result of a breakdown, it is a favourable situation.

\section{Acknowledgements}

The Programme of the Polish Ministry of Science and Higher Education - the Regional Initiative of Excellence financed by the Polish Ministry of Science and Higher Education on the basis of the contract no 025/RID/2018/19 of 28 December 2018, the amount of funding: 12 million PLN.

\section{REFERENCES}

1. Bao W, Zou H., Gan S., Xu X., JI G., Zheng K. 2013. Adsorption of heavy metal ions from aqueous solutions by zeolite based on oil shale ash: kinetic and equilibrium studies. Chemical Research in Chinese Universities, 29, 126-131.

2. Deng L., Xu Q., Wu H. 2016. Synthesis of zeolitelike material by hydrothermal and fusion methods using municipal solid waste fly ash. Procedia Environmental Sciences, 31, 662-667.

3. EPA Regulations on Land Disposal Restrictions. 1991. Appendix II - Toxicity Characteristic Leaching Procedure, 161:1877. The Bureau of National Affaris, Inc.,Washington D.C. 20037

4. Fan Y., Zhang F.S., Zhu J., Liu Z. 2008. Effective utilization of waste ash from MSW and coal cocombustion power plant - zeolite synthesis, Journal of Hazardous Materials, 153, 382-388.

5. Filipiak J. 2011. Fly Ash in Construction Industry. Strength Tests of Soil Stabilized with Mixture of Ash and Cement. Annual Set the Environment Protection, 13, 1043-1054, (in Polish).

6. Franus W. 2012. The use of zeolites produced from fly ash to remove impurities from water and sewage.
Polish Academy of Sciences, Lublin (in Polish).

7. General Statistic Office, 2019, https://bdl.stat.gov. $\mathrm{pl}$, (in Polish).

8. Kappel A., Ottosen L.M., Kirkelund G.M. 2017. Colour, compressive strength and workability of mortars with an iron rich sewage sludge ash. Construction and Building Materials, 157, 1199-1205.

9. Kirov G., Filizova L., Petrov O. 1997. Natural Zeolites-SOFIA95. Minato H.: Standardization of methods for zeolite speciality determination and techniques for zeolite resources utilization. PENSOFT, Sofia-Moscow.

10. Latosińska J. 2016. Zeolitization of sewage sludge ash with a fusion method. Journal of Ecological Engineering, 17, 138-146.

11. Latosińska J. 2017. The influence of temperature and time of sewage sludge incineration on the mobility of heavy metals. Environment Protection Engineering, 44, 105-122.

12. Latosińska J. 2019. Modification of municipal sewage sludge ash by zeolitization - selected issues. Kielce University of Technology. Kielce (in Polish).

13. Latosińska J., Gawdzik J. 2012. The effect of incineration temperatures on mobility of heavy metals in sewage sludge ash. Environment Protection Engineering, 14, 31-44.

14. National Waste Management Plan 2022, 2016, (in Polish).

15. Pimraksa K., Chindaprasirt P., Setthaya N. 2010. Synthesis of zeolite phases from combustion byproducts. Waste Management and Resources, 28, 1122-1132.

16. Regulation of the Ministry of Economy of 16.07.2015, on the acceptance of waste for storage in landfills, Journal of Laws, No 0, item 1277, (in Polish).

17. Regulation of the Ministry of Health of 7 December 2017 on the quality of water intended for human consumption, Journal of Laws No 0, item 2294, (in Polish).

18. Smol M., Kulczycka J., Henclik A, Gorazda K., Wzorek Z. 2015. The possible use of sewage sludge ash (SSA) in the construction industry as a way towards a circular economy. Journal of Cleaner Production, 95, 45-54.

19. Zabielska-Adamska K. 2015. Combustion product of municipal sewage sludge as anthropogenic soil. Annual Set The Environment Protection, 17, 1286-1305, (in Polish).

20. Zhang Y., Leng Z., Zou F., Wang L., Chen S.S., Tsang D.C.W. 2018. Synthesis of zeolite A using sewage sludge ash for applicaton in warm mix asphalt. Journal of Cleaner Production, 172, 686-695. 